\title{
HAK UNTUK MENDAPATKAN RAWATAN KESIHATAN BAGI KOMUNITI TRANSGENDER DI MALAYSIA: SUATU KELOMPANGAN ANTARA PERATURAN DENGAN AMALAN
}

\section{(The Right to Health Care for the Transgender Community in Malaysia: The Gap between Rules and Practice)}

Nur Insyirah Jasri

syirah.jasri2103@gmail.com

\section{Rohaida Nordin*}

rohaidanordin@um.edu.my

Fakulti Undang-undang, Universiti Kebangsaan Malaysia.

Pengarang koresponden (Corresponding author):*

Rujukan artikel ini (To cite this article): Nur Insyirah Jasri \& Rohaida Nordin. (2022). Hak untuk mendapatkan rawatan kesihatan bagi komuniti transgender di Malaysia: Suatu kelompangan antara peraturan dengan amalan. Kanun: Jurnal Undang-undang Malaysia, 34(1), 113-140. http://doi.org. 10.37052/kanun.34(1)no6

\begin{tabular}{|lllllll|}
\hline $\begin{array}{l}\text { Peroleh: } \\
\text { Received: }\end{array}$ & $6 / 9 / 2021$ & $\begin{array}{l}\text { Semakan: } \\
\text { Revised }\end{array}$ & 11/11/2021 & $\begin{array}{l}\text { Terima: } \\
\text { Accepted: 25/12/2021 }\end{array}$ & $\begin{array}{l}\text { Terbit dalam talian: } \\
\text { Published online }\end{array}$ & $2 / 1 / 2022$ \\
\hline
\end{tabular}

\begin{abstract}
Abstrak
Hak kesamarataan terhadap warganegara atas alasan jantina telah dijamin di bawah Perkara 8(2) Perlembagaan Perseketuan dan triti hak asasi manusia antarabangsa. Walaupun hak kesamarataan mereka telah dijamin, golongan transgender mendakwa mereka masih menerima diskriminasi dan layanan tidak sama rata terutamanya ketika mendapatkan rawatan kesihatan. Oleh itu, objektif kajian ini adalah untuk melihat sejauh mana kewujudan undang-undang domestik dan perjanjian antarabangsa yang telah meletakkan piawaian tertinggi mengenai layanan terhadap individu yang mempunyai kecelaruan identiti jantina atau transgender diaplikasikan di Malaysia. Kaedah yang digunakan dalam menyelesaikan kajian
\end{abstract}


ini adalah melalui rujukan dan juga temu bual. Dalam kajian ini, pengkaji berjaya melihat bahawa hak kesamarataan yang dijamin di bawah Perlembagaan Persekutuan adalah tidak mutlak dan tertakluk pada undang-undang lain yang berkaitan. Penyelidik juga berjaya mengenal pasti beberapa alternatif yang boleh digunakan agar permasalahan berkaitan diskriminasi terhadap golongan transgender ini dapat diselesaikan, iaitu dengan penguatkuasaan undang-undang yang lebih tegas dan penetapan suatu tindakan yang lebih berat oleh kerajaan Malaysia terhadap pengamal kesihatan apabila berlaku diskriminasi terhadap golongan transgender.

Kata kunci: Transgender, kesamarataan, undang-undang domestik, undang-undang antarabangsa, Kementerian Kesihatan Malaysia, Perlembagaan Persekutuan

\section{Abstract}

Equality of citizens on the grounds of gender is guaranteed under Article 8(2) of the Federal Constitution and international human rights treaties. Despite this guarantee of right, transgender people claim that they are still discriminated and receive unequal treatment, especially when accessing health care. Therefore, the objective of this study is to determine the extent to which the existence of domestic laws and international laws have placed the highest standard of treatment for individuals with gender identity disorder or transgender people in Malaysia. The methods used in completing this study were through referrals and interviews. In this study, the researcher successfully found that the right to equality guaranteed under the Federal Constitution is not absolute and is subjected to other relevant laws. The researcher also managed to identify several alternatives that can be employed to solve the problems related to discrimination against transgender people, namely with more stringent law enforcement and actions by the Malaysian government on health practitioners in the event of discriminatory treatment against transgender people.

Keywords: Transgender, equality, domestic law, international law, Ministry of Health Malaysia, Federal Constitution 


\section{PENDAHULUAN}

Hak asasi manusia ialah hak dan kebebasan untuk semua orang. Mereka berhak mendapatkannya tanpa mengira latar belakang individu. Sebagai manusia, kesihatan merupakan aspek penting yang perlu diambil berat oleh setiap lapisan masyarakat. Akses kesihatan adalah penting tanpa mengira umur, pangkat, jumlah aset dan latar belakang kaum serta agama. Kesihatan yang baik mendorong manusia menunaikan tanggungjawab harian sebagai pekerja dan pelajar serta mampu melahirkan seorang individu yang produktif dan berdaya saing sekali gus memberikan impak positif kepada pembangunan masyarakat. Hak kesihatan ialah hak asasi manusia. Menjadi tanggungjawab setiap negara untuk memberikan perkhidmatan kesihatan yang terbaik buat semua lapisan masyarakatnya.

Artikel ini akan membincangkan tentang piawaian hak kesihatan yang tertinggi yang diperuntukkan dalam perjanjian antarabangsa, undangundang serantau serta undang-undang antarabangsa yang dapat dijadikan panduan kepada semua negara anggota Pertubuhan Bangsa-Bangsa Bersatu (PBB). Seterusnya, kedudukan undang-undang dan dasar yang berkaitan di Malaysia juga akan dikaji bagi menunjukkan sejauh mana hak terhadap kesihatan dalam kalangan semua individu di Malaysia ini dilindungi.

Secara asasnya, LGBT merupakan singkatan bagi golongan Lesbian, Gay, Bixesual dan Transgender yang secara umumnya merujuk golongan yang mempunyai orientasi seksual dan kecelaruan identiti jantina yang berbeza daripada individu biasa. Transgender merupakan satu terma yang digunakan untuk menggambarkan identiti jantina, ekspresi seksual dan perbezaan tingkah laku jantina yang berbeza dengan jantina asal ketika kelahiran. Sebagai contohnya, walaupun pada mulanya mereka dilahirkan sebagai seorang lelaki atau wanita, pada suatu peringkat dalam kehidupan, mereka secara perlahan-lahan mengubah tingkah laku mereka yang bertentangan dengan jantina asal.

Adalah penting untuk dijelaskan di sini bahawa skop dan tujuan artikel ini ditulis bukanlah untuk membincangkan status undang-undang komuniti transgender dan hak-hak mereka secara am di Malaysia. Kajian ini hanya menfokuskan kepada hak komuniti transgender terhadap rawatan kesihatan yang mana dihujahkan sama seperti individu lain di Malaysia. 


\section{KESAKSAMAAN DALAM HAK KESIHATAN}

Kesaksamaan dan antidiskriminasi merupakan hak asasi manusia yang sering dibincangkan dalam undang-undang antarabangsa. Semua negara yang merupakan negara anggota PBB perlu menjalankan tanggungjawab undang-undang untuk mempromosikan dan melindungi hak kesamarataan dan antidiskriminasi. Ketua Pengarah Pertubuhan Kesihatan Sedunia (WHO), Dr Tedros Adhanom Ghebreyesus (2017) berkata nikmat kesihatan yang tertinggi ialah salah satu hak asasi tanpa membezakan bangsa, agama, kepercayaan politik, keadaan ekonomi mahupun sosial. Hak terhadap kesihatan pula bermaksud bahawa semua orang berhak dalam mengawal kesihatan dan tubuh mereka sendiri, termasuk memiliki akses kepada maklumat dan perkhidmatan seksual tanpa berlaku sebarang keganasan dan diskriminasi (Tedros Adhanom Ghebreyesus, 2017). Fadilla \& Mohamatayuding (2017) mendefinisikan diskriminasi sebagai sebarang perbezaan, pengecualian atau sekatan yang dibuat menyebabkan tujuan sesuatu perkara itu terjejas. Kaspert Lippert-Rasmussen (2013) berkata diskriminasi ialah pembezaan terhadap sesuatu individu atau perkara yang tidak membawa keuntungan. Diskriminasi dalam akses kesihatan merupakan perkara utama yang menghalang pembangunan negara.

Malaysia merupakan negara anggota PBB dan telah menyelaraskan falsafah, konsep dan norma yang ditetapkan dalam Deklarasi Hak Asasi Manusia Sejagat 1948 (DHAMS) apabila piawaian tertinggi hak asasi manusia ditetapkan untuk semua orang dan semua negara termasuklah hak kesihatan (Portal Pejabat Peguam Negara Malaysia, 2016). Hak kesihatan telah jelas dinyatakan dalam Deklarasi Hak Asasi Manusia Sejagat (DHAMS), perjanjian antarabangsa dan hampir kesemua perlembagaan negara-negara lain. Selain peruntukan yang ditetapkan dalam DHAMS, Malaysia juga mematuhi prinsip yang ditetapkan dalam instrumen hak asasi manusia antarabangsa. Namun begitu, perkara ini tertakluk pada dasar, undang-undang dan peruntukan Perlembagaan Persekutuan Malaysia. Hal ini disokong oleh peruntukan Seksyen 2 Akta Suruhanjaya Hak Asasi Manusia Malaysia 1999 (Akta 597) bahawa hak asasi manusia merujuk kebebasan asasi yang terkandung dalam Bahagian II Perlembagaan Persekutuan Malaysia. Tambahan lagi, Seksyen 4(4) Akta 597 memperuntukkan bahawa DHAMS hendaklah diberikan perhatian setakat mana pelaksanaannya selaras dengan Perlembagaan Persekutuan. 


\section{UNDANG-UNDANG ATAU PERJANJIAN ANTARABANGSA}

Pada peringkat antarabangsa, terdapat deklarasi serta perjanjian yang sudah menggariskan piawaian tertinggi bagi hak kesihatan untuk dijadikan panduan bagi negara anggota PBB. Walaupun Malaysia tidak menandatangani semua perjanjian yang bakal dibincangkan, namun hal ini boleh dijadikan panduan dan amalan untuk dicontohi oleh pengamal kesihatan di Malaysia.

\section{Pertubuhan Kesihatan Sedunia (World Health Organization)}

Pertubuhan Kesihatan Sedunia atau dikenali sebagai World Health Organization (WHO) merupakan agensi yang bertanggungjawab atas kesihatan awam antarabangsa. Perlembagaan WHO telah diterima pakai di Persidangan Kesihatan Antarabangsa yang diadakan di New York dari 19 Jun hingga 22 Julai 1946 apabila ditandatangani pada 22 Julai 1946 oleh wakil-wakil 61 buah negara dan dikuatkuasakan pada 7 April 1948. Menurut WHO, hak untuk kesihatan merangkumi keadaan fizikal dan mental yang sempurna serta kesejahteraan sosial. Hak ini termasuklah bahawa setiap individu berhak menikmati pelbagai kemudahan dan keadaan yang perlu untuk kesihatan yang baik. Hak-hak yang terkandung dalam Perlembagaan WHO boleh dibahagikan kepada dua kategori, iaitu pertama, hak yang berkaitan dengan penjagaan kesihatan. Keduanya, hak yang berkaitan dengan keadaan hidup umum yang memberikan kesan kepada kesihatan, seperti air yang bersih dan perlindungan yang selamat.

Hak untuk penjagaan kesihatan menurut Perkara 1 Perlembagaan WHO adalah apabila seseorang individu itu berhak kepada sistem kesihatan yang cekap, berkesan dan merangkumi penjagaan kesihatan yang baik. Selain itu, Perkara 1 menyatakan bahawa semua negara anggota WHO, perlu bekerjasama mempromosi dan melindungi hak kesihatan rakyat dengan menerima pakai peruntukan yang ditetapkan Perlembagaan WHO dalam dasar undang-undang negara tersebut. Hal ini kerana, piawaian hak kesihatan yang tertinggi ditetapkan oleh WHO adalah apabila hak asasi setiap manusia diberikan tanpa melihat perbezaan bangsa, agama, kepercayaan politik, keadaan ekonomi mahupun sosial. Oleh itu, kerajaan negara anggota perlu bertanggungjawab memastikan kesihatan rakyatnya dipenuhi dengan akses kesihatan yang cukup. 


\section{Deklarasi Hak Asasi Manusia Sejagat 1948 (Universal Declaration of Human Rights 1948)}

Deklarasi Hak Asasi Manusia Sejagat 1948 mengandungi 30 perkara yang jelas menyebut tentang jaminan hak asasi manusia kepada semua orang termasuklah hak kesihatan. Perkara 1 Deklarasi ini menjelaskan bahawa semua manusia mempunyai kebebasan dan kesaksamaan terhadap hak dan martabat. Semua orang tanpa mengira latar belakang patut bertindak sesama sendiri melalui semangat persaudaraan. Di sini dapat ditafsirkan bahawa, jika seseorang itu transgender ataupun tidak, mereka berhak terhadap hak dan martabat sama seperti individu lain. Perkara 2 pula menyatakan bahawa semua individu itu berhak kepada semua hak dan kebebasan tanpa mengira warna kulit, kaum, politik, agama, bahasa dan juga menyatakan secara khusus tentang jantina.

Seterusnya, Perkara 3 menjelaskan bahawa semua individu mempunyai hak untuk hidup, kebebasan dan juga keselamatan diri. Perkara 6 pula menyatakan bahawa semua orang mempunyai hak untuk diiktiraf di sisi undang-undang. Oleh itu, dalam konteks ini, Perkara 6 memberikan hak kepada transgender supaya mereka dikenali dari segi undang-undang. Perkara 7 menyatakan bahawa golongan transgender ini mempunyai hak persamaan di sisi undang-undang. Hal ini jelas menyebut berkaitan perlindungan undang-undang yang wajar diberikan kepada setiap individu. Oleh itu, golongan transgender yang mengalami diskriminasi dan tidak mendapat layanan yang sama rata ketika mendapatkan rawatan kesihatan berhak mendapatkan keadilan.

Perkara 25 pula menerangkan bahawa setiap individu berhak untuk mendapatkan taraf hidup yang sesuai bagi kesihatan dan kebajikan diri dan keluarganya dan hal ini merangkumi makanan, pakaian, perumahan, perubatan, penjagaan serta perkhidmatan sosial yang perlu. Misalnya, warga emas serta ibu dan anak berhak mendapatkan perlindungan serta pemberian bantuan khas secara berkala. Seterusnya, semua kanak-kanak sama ada dilahirkan dalam perkahwinan atau di luar perkahwinan (luar nikah) juga berhak menikmati perlindungan sosial yang sama. Melalui Perkara 25 juga, negara harus mengambil tindakan untuk memastikan semua rakyat menikmati taraf hidup yang mencukupi. Perkara ini mengiktiraf makanan, pakaian, perumahan, penjagaan kesihatan serta perkhidmatan sosial sebagai komponen yang paling penting untuk mencapai taraf hidup yang sejahtera. Oleh itu, Malaysia melalui Kementerian Kesihatan Malaysia (KKM) harus memastikan semua pengamal kesihatan di 
Malaysia memberikan layanan yang sama rata kepada semua yang ingin mendapatkan akses kesihatan tanpa mengambil kira latar belakang, umur, agama, bahasa dan juga jantina mereka.

\section{Waad Antarabangsa Hak Ekonomi, Sosial dan Budaya 1966 (International Convention on Economic, Social \& Cultural Rights 1966)}

Waad Antarabangsa Hak Ekonomi, Sosial dan Budaya (ICESCR) merupakan perjanjian multilateral yang diterima pakai oleh Perhimpunan Agung PBB pada 16 Disember 1966. ICESCR merupakan sebahagian daripada Rang Undang-Undang Hak Asasi Manusia Antarabangsa bersama dengan Deklarasi Hak Asasi Manusia Sejagat dan juga Waad Antarabangsa mengenai Hak-Hak Sivil dan Politik (ICCPR). Jawatankuasa PBB memantau perjanjian ini terutamanya mengenai hak ekonomi, sosial dan budaya. Negara yang menjadi anggota kepada konvensyen ini terus komited bekerja dalam pemberian hak ekonomi, sosial dan budaya termasuk hak buruh, hak untuk pendidikan, hak untuk kesihatan dan hak taraf. Sehingga Januari 2020, konvensyen ini mempunyai 170 negara anggota. Walau bagaimanapun, Malaysia tidak menandatanganinya dan bukanlah negara anggota konvensyen tersebut.

Perkara 2(1) ICESCR menyatakan bahawa, negara anggota mempunyai kewajipan untuk menjamin kenikmatan penuh hak dengan cara yang progresif berkaitan dengan hak-hak yang dinyatakan dalam perjanjian ini. Hal ini kerana, sesetengah negara anggota mempunyai kekangan dan memerlukan masa untuk melaksanakan peruntukan yang dinyatakan di dalam perjanjian. Implikasinya, beberapa hak dalam Waad ini patut dilindungi seperti hak kesihatan yang dianggap subjek kepada kesedaran progresif. Hak kesihatan secara progresif dalam konteks ini bermaksud bahawa, pembayaran untuk perkhidmatan penjagaan kesihatan mestilah berdasarkan prinsip ekuiti, iaitu isi rumah dengan pendapatan yang rendah tidak boleh dibebani secara tidak adil dengan perbelanjaan kesihatan berbanding dengan isi rumah yang lebih kaya. Selain itu, peruntukan sumber kesihatan tidak boleh memihak kepada rawatan kesihatan yang mahal, dan hanya segelintir individu sahaja yang dapat mengaksesnya. ICESCR mengakui bahawa kerajaan mempunyai kekangan disebabkan sumber yang terhad. Namun begitu, ICESCR telah mewajibkan kerajaan negara anggota untuk menjamin pelaksanaan hak kesihatan tanpa sebarang diskriminasi. Negara anggota juga bertanggungjawab untuk memastikan penyediaan semua kemudahan, barang dan perkhidmatan kesihatan (Gillian MacNaughton, 2013). 
Perkara 12 ICESCR pula menyatakan bahawa negara anggota perlu mengakui dan menyediakan hak kepada semua individu untuk menikmati taraf kesihatan fizikal dan mental yang tertinggi. Misalnya, sebagai salah satu inisiatif untuk memberikan komuniti transgender di Thailand peluang menikmati taraf kesihatan yang khusus, Thai Red Cross memulakan langkah dengan membuka pusat kesihatan pertama yang memberikan perkhidmatan eksklusif kepada komuniti transgender yang dinamakan sebagai The Tangerine Community Health Centre. Klinik ini dibuka menurut undang-undang domestik di Thailand yang mengiktiraf status undang-undang komuniti transgender. Oleh yang demikian, klinik ini dibuka dengan tujuan untuk memberikan perkhidmatan kesihatan yang berkualiti seperti kaunseling psikososial, hormone administration dan pap smears oleh kakitangan transgender yang terlatih dan pengamal kesihatan yang mahir dalam bidang perubatan. Oleh yang demikian, stigma dan diskriminasi dapat dikurangkan terhadap golongan transgender ketika mereka mendapatkan rawatan kesihatan (Roux, 2015).

Selain itu, negara anggota harus memperbaik serta memajukan semua aspek kebersihan, dari segi alam sekitar dan sektor perindustrian. Negara juga bertanggungjawab untuk mencegah, merawat dan mengawal penyakit epidemik, endemik, pekerjaan dan lain-lain serta mewujudkan keadaan yang memastikan semua perkhidmatan perubatan sentiasa tersedia sekiranya berlaku sebarang penyakit. Dalam konteks ini, kesihatan difahami bukan hanya sebagai hak untuk menjadi sihat, tetapi hak untuk mengawal kesihatan tubuh sendiri seperti pembiakan dan kebebasan daripada gangguan penyeksaan atau eksperimen perubatan. Semua negara anggota ICESCR harus melindungi hak ini dengan memastikan bahawa setiap individu mempunyai akses kepada faktor utama penentu kesihatan, seperti air yang bersih dan berkualiti, sanitasi, makanan serta pemakanan, perumahan dan melalui sistem penjagaan kesihatan yang komprehensif tertakluk pada bidang kuasa negara anggota. Kemudahan ini haruslah tersedia untuk semua individu tanpa sebarang diskriminasi serta boleh diakses oleh semua (Pejabat Pesuruhjaya Hak Asasi Manusia PBB, 2008).

\section{Konvensyen Menghapuskan sebarang Bentuk Diskriminasi terhadap Wanita (Convention on the Elimination of All Forms of Discrimination against Women 1979 (CEDAW)}

Convention on the Elimination of All Forms of Discrimination Against Women atau lebih dikenali sebagai CEDAW merupakan perjanjian 
antarabangsa mengenai hak wanita yang bertujuan untuk memastikan hak wanita dilindungi dan mewajibkan negara anggota untuk memenuhi hakhak yang dinyatakan dalam Konvensyen ini. Konvensyen ini diterima pakai pada tahun 1979 oleh Perhimpunan Agung PBB dan sering digambarkan sebagai undang-undang hak asasi antarabangsa bagi kaum wanita. CEDAW mempunyai 30 Perkara yang menjelaskan hak wanita daripada pelbagai aspek. Malaysia telah meratifikasi konvensyen ini dengan membuat reservasi terhadap beberapa peruntukan pada tahun 1995. Namun begitu, Malaysia telah menarik balik reservasi terhadap Perkara 2(f), Perkara 9(1), Perkara 16(1b), Perkara (1d), Perkara (1e) dan Perkara 1(h) pada tahun 1998 kerana komen yang telah dibuat oleh negara lain seperti Finland, Germany, Netherlands dan Norway. Walau bagaimanapun, Malaysia tetap mengekalkan reservasi terhadap Perkara 9 (2), Perkara 16 (1)(a), Perkara 16 (1)(c), Perkara (16)(1)(f) dan Perkara 16 (1)(g).

Perkara 1 CEDAW memberikan definisi diskriminasi dan menjelaskan perkara asas untuk mengatasi serta menghilangkan diskriminasi. Perkara 2 hingga Perkara 4 telah menggariskan kewajipan negara anggota melalui undang-undang serta polisi domestik yang harus dilakukan bagi menghilangkan sebarang unsur diskriminasi. Perkara 5 sehingga Perkara 16 menentukan bidang-bidang yang perlu diambil perhatian oleh negara anggota bagi menangani serta menghilangkan diskriminasi mengikut langkah-langkah yang wajar diambil melalui Perkara 1 sehingga Perkara 4. Perkara-perkara yang dimaksudkan ialah peranan setiap jantina, stereotaip serta amalan adat yang memudaratkan wanita, aktiviti pelacuran dan pemerdagangan manusia, kehidupan politik dan awam, penyertaan pada peringkat antarabangsa, kewarganegaraan, pendidikan, pekerjaan, penjagaan kesihatan, perkahwinan dan hubungan keluarga serta faedah yang diperoleh dari aspek sosial dan ekonomi. Perkara 17 sehingga Perkara 22 pula menerangkan secara terperinci mengenai pertubuhan dan peranan Jawatankuasa CEDAW. Selain menyenaraikan dan mendefinisikan perkara-perkara yang berbentuk diskriminasi terhadap kaum wanita, CEDAW juga digubal untuk menegakkan 3 prinsip asas. "Susbstantive equality" yang membawa maksud pengiktirafan berkaitan dengan peluang yang sama, akses yang sama serta hasil yang sama buat kaum wanita agar tidak dipinggirkan oleh masyarakat, prinsip antidiskriminasi serta prinsip kewajipan negara anggota untuk menegakkan Perkara-Perkara yang terkandung di dalam CEDAW (Syarifah Syahirah, 2010). Perkara 1 khusunya telah menerangkan bahawa wanita seharusnya mendapat perlindungan di bawah Konvensyen ini agar segala bentuk diskriminasi 
terhadap mereka Perkataan-perkataan seperti "perbezaan, pengecualian serta pembatasan" digunakan secara meluas untuk menunjukkan pendekatan hak asasi manusia dalam memerangi diskriminasi terhadap wanita. Namun begitu, apakah nasib individu yang bergelar transwanita? Adakah mereka tergolong dalam golongan wanita atau sebaliknya?

Dalam aspek hak kesihatan pula, Perkara 12 CEDAW telah menyatakan bahawa semua negara anggota harus mengambil langkah yang efektif bagi memastikan tiada sebarang diskriminasi berlaku terhadap wanita dalam mengakses perkhidmatan kesihatan dan perkara yang berkaitan dengan perancangan keluarga. Namun begitu, di Malaysia, walaupun negara kita meratifikasi perjanjian ini, kerajaan menyatakan sebarang persetujuan yang dilakukan oleh kerajaan adalah tertakluk dan bersandarkan undang-undang syariah Islam dan Perlembagaan Persekutuan. Undang-undang syariah di Malaysia tidak mengiktiraf status undang-undang golongan transgender atau disebut sebagai khunsa walaupun telah ada beberapa penerimaan intersex kerana sudah ada bukti biologi yang jelas seperti pesakit yang menghidapi khunsa nyata. Larangan ini sudah jelas disebut, dalam akta dan enakmen negeri. Sebagai contoh, Seksyen 28 Akta Kesalahan Jenayah Syariah (Wilayah Persekutuan) 1997 memperuntukkan manamana orang lelaki yang memakai pakaian perempuan dan berlagak seperti seorang perempuan di mana-mana tempat awam dengan tujuan yang tidak bermoral adalah melakukan suatu kesalahan dan jika didapati bersalah, boleh disabitkan dengan denda tidak melebihi satu ribu ringgit atau dipenjarakan selama tempoh tidak melebihi satu tahun atau kedua-duanya sekali. Contoh kedua, Enakmen 9 tahun 1995 Enakmen Jenayah Syariah (Selangor) 1995 Bahagian IV-Kesalahan Yang berhubungan dengan Kesusilaan yang memperuntukkan mana-mana lelaki yang memakai pakaian perempuan atau berlagak seperti perempuan dikira melakukan suatu kesalahan dan apabila disabitkan kesalahan boleh dikenakan denda tidak melebihi satu ribu ringgit atau dipenjarakan selama tempoh tidak melebihi enam bulan atau kedua-duanya sekali.

Di Malaysia, untuk mencapai hak kesamarataan dan hak untuk mendapat perlindungan yang sama rata adalah perkara yang rumit. Hal ini kerana, Malaysia mempunyai sistem perundangan yang terdiri daripada undangundang pada peringkat Persekutuan dan pada peringkat negeri. Undangundang syariah berada di bawah bidang kuasa negeri dan disebabkan itu, setiap negeri boleh mentadbir undang-undang Syariah dengan menghukum golongan transgender secara berbeza (Human Rights Watch, 2014). 


\section{The Yogyakarta Principles 2017 (Prinsip Yogyakarta)}

The Yogyakarta Principles merupakan dokumen hak asasi manusia yang khusus memperincikan mengenai orientasi seksual dan identiti jantina. Prinsip Yogyakarta ini dilancarkan sebagai piagam global pada 26 Mac 2007 di Majlis Hak Asasi Manusia PBB, Geneva dan telah dibentangkan dalam persidangan PBB di New York pada 7 November 2007. Prinsipprinsip tersebut menjelaskan secara terperinci bahawa hak asasi manusia antarabangsa dapat diaplikasikan untuk menangani masalah orientasi seksual dan identiti jantina. Selain itu, prinsip ini menegaskan bahawa undang-undang antarabangsa di semua negara terikat dan perlu memastikan semua individu diberikan layanan yang sama rata. Prinsip ini mengakui golongan LGBT dilahirkan bebas serta layak terhadap martabat dan hak serta berpendapat bahawa piawaian hak asasi manusia dapat ditafsirkan dari pelbagai aspek, iaitu dari segi orientasi seksual dan identiti jantina. Hal ini termasuklah, hak kesihatan, hak pekerjaan, hak pendidikan, hak berkumpul dan lain-lain.

Menurut Prinsip 2 dalam The Yogyakarta Principles, individu yang mengalami kecelaruan orientasi seksual dan identiti jantina tidak boleh didiskriminasi dan mereka berhak pada konsep kesamarataan di sisi undangundang. Selain itu, mereka juga turut berhak mendapatkan perlindungan undang-undang tanpa diskriminasi. Di samping itu, mereka juga berhak untuk diiktiraf sebagai seorang individu yang bebas selain diberikan hak untuk menikmati hak asasi manusia dan juga kebebasan asasi.

Prinsip 17 dalam The Yogyakarta Principles pula telah meletakkan piawaian yang tertinggi dari aspek kesihatan. Setiap orang berhak kepada piawaian kesihatan fizikal dan mental yang tertinggi, tanpa diskriminasi atas dasar orientasi seksual atau identiti jantina. Kesihatan seksual yang melibatkan sistem reproduktif seperti gender reaffirming surgery dan hormone therapy merupakan aspek penting hak ini. Oleh itu, The Yogyakarta Principles mengakui hak golongan transgender untuk mendapatkan akses kepada kedua-dua rawatan ini agar dapat merealisasikan impian mereka untuk mengubah bentuk fizikal badan.

Berdasarkan dua prinsip ini, dapat kita lihat bahawa undang-undang antarabangsa telah meletakkan piawaian kesihatan yang tertinggi dengan memberi rawatan yang terbaik dan cekap untuk meningkatkan mutu kesihatan seseorang tanpa mengira orientasi seksual dan identiti jantina mereka. Prinsip ini merupakan soft law, maka undang-undang ini tidak 
mempunyai kuasa mengikat bagi negara-negara anggota yang tidak mengiktiraf The Yogyakarta Principles seperti Malaysia.

\section{The Universal Periodic Review (UPR)}

Universal Periodic Review (UPR) ialah proses yang melibatkan kajian semula rekod hak asasi manusia daripada semua negara anggota PBB. UPR ialah state-driven process di bawah naungan Majlis Hak Asasi Manusia. UPR memberikan peluang kepada semua negara anggota untuk menyatakan tindakan yang telah mereka lakukan untuk memperbaik situasi hak asasi manusia di negara mereka serta memenuhi kewajiban hak asasi mereka (OHCHR 2017).

Perlindungan undang-undang terhadap golongan transgender diperkenalkan dan didokumentasikan dalam kajian berkala yang dilakukan melalui UPR. Prestasi Malaysia telah disemak melalui UPR pada tahun 2013 dan beberapa negara telah menyatakan keprihatinan serta membuat cadangan kepada Malaysia tentang hak asasi manusia terhadap golongan LGBT dan mengenai diskriminasi berdasarkan identiti jantina dan orientasi seksual. Namun begitu, Malaysia tidak menerima sebarang cadangan yang melibatkan orientasi seksual mahupun mengenai identiti jantina dalam UPR pada tahun 2013 tersebut. Perkara yang sama berlaku pada tahun 2009. Dalam pernyataan yang dikeluarkan oleh Majlis Hak Asasi Manusia mengenai pelanggaran hak asasi manusia terhadap golongan LGBT, kerajaan Malaysia telah dengan jelas menyatakan bahawa perkara yang melibatkan LGBT akan ditangani secara berhati-hati selaras dengan budaya, ajaran agama, norma sosial dan undang-undang domestik (Asia Pacific Transgender Network, 2017).

Pada tahun 2018, Malaysia telah mengambil perhatian terhadap cadangan yang dikemukakan oleh negara anggota lain berkenaan dengan LGBT namun, Malaysia masih tidak menerima pakai cadangan berkaitan dengan LGBT sepenuhnya mahupun secara separa. Kerajaan Malaysia menyedari bahawa kedaulatan undang-undang bergantung pada persetujuan masyarakat yang menjadi asas demokrasi di negara ini. Walau bagaimanapun, kerajaan Malaysia menegaskan bahawa negara ini tidak mendiskriminasi komuniti LGBT dan hak mereka seharusnya dilindungi selaras dengan peruntukan undang-undang negara (Universal Periodic Review, 2018). 


\section{Undang-Undang atau Perjanjian pada peringkat Rantau Asia}

Undang-undang serantau Asia merupakan perjanjian yang ditandatangani dan diratifikasi oleh negara anggota yang merupakan anggota kepada Persatuan Negara-negara Asia Tenggara (ASEAN). ASEAN ialah kumpulan serantau yang mempromosikan kerjasama, ekonomi, politik dan keselamatan dalam kalangan sepuluh anggotanya, iaitu Vietnam, Thailand, Singapura, Filipina, Myanmar, Malaysia, Laos, Indonesia, Kemboja dan Brunei (Carlos Galina, 2019).

Pada tahun 2009, ASEAN telah menubuhkan ASEAN Intergovernmental Commission on Human Rights untuk mempromosikan serta menegakkan hak asasi manusia dalam kalangan 10 negara ASEAN ini. Pada pertengahan tahun 2010, ASEAN Intergovernmental Commission on Human Rights telah merangka Deklarasi Hak Asasi Manusia ASEAN dan deklarasi ini diterima pakai oleh semua negara anggota ASEAN semasa mesyuaratnya di Phnom Penh, Kemboja pada tahun 2012. Deklarasi ini telah menjelaskan komitmen negara-negara anggota ASEAN tentang hak asasi manusia. Deklarasi ini merangkumi 40 perenggan di bawah 6 tajuk.

Berdasarkan Perkara 1, deklarasi ini menyatakan bahawa semua individu yang dilahirkan adalah sama rata di sisi undang-undang. Setiap rakyat negara ASEAN harus berkerjasama antara satu sama lain dan perlu mewujudkan semangat kemanusiaan. Perkara 2 pula menyatakan bahawa bangsa, jantina, umur, bahasa, agama, politik dan status lain tidak boleh menjadi penghalang seseorang itu daripada mendapatkan hak kebebasan. Perkara 3 pula menyatakan bahawa setiap orang mempunyai hak pengiktirafan, iaitu semua orang adalah sama rata di sisi undang-undang. Semua individu berhak mendapat hak asasi tanpa diskriminasi dan berhak menerima perlindungan undang-undang. Perkara 6 menjelaskan bahawa menjadi tanggungjawab utama semua negara anggota ASEAN untuk melindungi semua hak asasi manusia dan kebebasan peribadi. Beralih pada aspek kesihatan pula, Perkara 29 (1) menyatakan bahawa setiap individu mempunyai hak untuk menikmati piawaian kesihatan yang tertinggi, iaitu meliputi kesihatan fizikal, mental, reproduktif dan kemudahan perubatan yang mudah dicapai. Deklarasi ini tidak menyatakan dengan jelas tentang hak asasi yang perlu diberikan kepada golongan LGBT, namun telah menyatakan bahawa setiap orang mempunyai kebebasan individu dan bebas daripada penangkapan tidak berasas, kebebasan untuk bergerak, kebebasan beragama dan kebebesan bersuara. Perkara 29 (2) pula menyatakan bahawa negara anggota ASEAN harus memastikan stigma, 
penafian hak dan diskriminasi tidak seharusnya berlaku kepada pesakit HIV/AIDS ketika mereka ingin mendapatkan penjagaan dan rawatan kesihatan.

Kesimpulannya, deklarasi ini menekankan tahap hak kesihatan tertinggi yang boleh dijadikan panduan bagi negara anggota ASEAN. Dari sudut undang-undang, deklarasi ini tidak mengikat namun menjadi panduan berkaitan dengan hak asasi manusia hasil daripada persetujuan 10 negara anggota ASEAN termasuklah Malaysia. Negara-negara ASEAN boleh menjadikan deklarasi ini sebagai panduan untuk mencapai piawaian yang tertinggi bagi melindungi hak golongan transgender daripada terus menerima diskriminasi dan penafian hak (Asia Pacific Transgender Network, 2017).

\section{UNDANG-UNDANG DOMESTIK}

Sistem perundangan Malaysia mengamalkan Perlembagaan bertulis dan mahkamah merupakan badan bebas yang berperanan besar untuk menjaga dan memelihara Perlembagaan. Prinsip Perlembagaan Malaysia terbentuk berdasarkan sistem dualisme perundangan. Dualisme perundangan ini merujuk pembahagian kuasa antara kerajaan Persekutuan dan negeri. Pada peringkat persekutuan, institusi yang mempunyai kuasa untuk membuat undang-undang bagi seluruh Malaysia ialah Parlimen. Pada masa yang sama, setiap 13 negeri di Malaysia mempunyai badan perundangan, iaitu Dewan Undangan Negeri (DUN) manakala Wilayah Persekutuan Kuala Lumpur, Putrajaya dan Labuan pula ditadbir oleh kerajaan Persekutuan serta ditadbir di bawah perundangan Kementerian Wilayah Persekutuan. DUN mempunyai kuasa untuk menggubal undang-undang bagi negerinya, manakala kerajaan negeri mempunyai kuasa untuk mentadbir negeri mengikut undang-undang tersebut. Menurut prinsip pembahagian kuasa ini, setiap satu badan perundangan mempunyai kuasa eksklusif yang tersendiri dan badan perundangan yang satu lagi tidak boleh melepasi kuasa pembahagian ini (Johan, 2019).

Mahkamah mempunyai peranan mentafsirkan undang-undang Persekutuan dan negeri. Setiap negeri mempunyai mahkamah syariah tersendiri untuk memutuskan segala perihal undang-undang syariah. Namun begitu, semua undang-undang haruslah selaras dengan Perlembagaan Persekutuan Malaysia. Bidang kuasa syariah adalah di bawah kuasa kerajaan negeri dan hanya terpakai kepada orang yang beragama Islam sahaja (Shamrahayu, 2014). Setiap individu transgender 
merupakan individu yang berhak kepada kenikmatan hak asasi manusia seperti yang terkandung dalam Bahagian II Perlembagaan Perseketuan.

Perkara 8 (1) menjelaskan bahawa semua orang adalah sama rata di sisi undang-undang dan berhak mendapatkan perlindungan yang sama rata di sisi undang-undang. Semua individu berhak mendapat layanan secara sama rata di sisi undang-undang agar keadilan hak asasi manusia dapat dicapai. Perkara 8 (2) pula menyatakan bahawa semua warganegara tidak boleh didiskriminasi atas alasan agama, ras, keturunan, tempat lahir atau jantina. Namun begitu, Artikel 8(2) Perlembagaan Persekutuan tidak mentafsirkan jantina secara menyeluruh dan ini termasuk golongan yang mempunyai orientasi seksual dan kecelaruan jantina yang berbeza seperti golongan transgender. Kedudukan transgender berdasarkan Artikel 8 (2) masih diperdebatkan.

Secara amnya, jantina hanya dilihat dari sudut binary, iaitu dua jantina yang terdiri daripada lelaki dan perempuan dan bukan dilihat dari sudut spektrum. Tambahan pula, di bawah undang-undang negeri, kesalahan penukaran jantina dan berkelakuan menyerupai jantina lain merupakan kesalahan yang besar di bawah undang-undang syariah. Enakmen setiap negeri melarang perbuatan lelaki yang menyerupai seperti seorang perempuan. Enakmen Jenayah Syariah negeri Kelantan, Perlis dan Kedah mengguna pakai terma "pondan" yang membawa maksud sama seperti lelaki memakai pakaian atau menyerupai seorang perempuan. Seksyen 55 Enakmen Jenayah Syariah negeri Perak, seksyen 30 Enakmen Jenayah Syariah negeri Selangor, seksyen 92 Enakmen Jenayah Syariah negeri Sabah, seksyen 7 Enakmen Jenayah Syariah negeri Kelantan, seksyen 7 Enakmen Jenayah Syariah negeri Kedah, seksyen 72 Enakmen Kesalahan Syariah negeri Melaka, seksyen 66 Enakmen Jenayah Syariah bagi Negeri Sembilan dan seksyen 92 Enakmen Kesalahan Jenayah Syariah negeri Sabah mengenakan pemenjaraan tidak melebihi enam bulan terhadap kesalahan ini. Seksyen 28 Enakmen Jenayah Syariah Negeri Pulau Pinang, seksyen 33 Enakmen Kesalahan Jenayah Syariah negeri Terengganu, seksyen 28 Enakmen Kesalahan Jenayah Syariah negeri Johor, seksyen 33 Enakmen Kesalahan Jenayah Syariah negeri Pahang serta seksyen 28 Akta Jenayah Syariah Wilayah Persekutuan mengenakan pemenjaraan tidak melebihi satu tahun. Tambahan lagi, seksyen 7 Enakmen Jenayah Dalam Syarak negeri Perlis pula mengenakan hukuman penjara tidak melebihi tiga tahun bagi kesalahan ini. Denda yang harus dibayar menurut setiap enakmen negeri adalah tidak melebihi RM1000 kecuali Negeri Perlis yang mengenakan denda yang lebih tinggi, iaitu tidak melebihi RM5000. Secara 
kesimpulannya, setiap negeri melarang perbuatan ini selaras dengan peruntukan undang-undang syariah, dan jika mereka didapati terlibat dalam perkara ini, hukuman berat akan dikenakan terhadap pesalah.

Seterusnya, fatwa juga telah dikeluarkan bagi menjelaskan hukum tentang golongan transgender. Muzakarah Jawatankuasa Fatwa Majlis Kebangsaan Bagi Hal Ehwal Ugama Islam Malaysia Kali Ke-4 yang bersidang pada 13-14 April 1982 memutuskan bahawa seseorang yang dilahirkan lelaki, hukumnya tetap lelaki manakala seseorang yang dilahirkan perempuan, hukumnya tetap perempuan walaupun (lelaki atau perempuan itu) berjaya menukarkan jantinanya melalui pembedahan. Pertukaran jantina daripada lelaki kepada perempuan ataupun sebaliknya, melalui pembedahan adalah haram dari segi syarak. Selain itu, Muzakarah Jawatankuasa Fatwa Kebangsaan pada Oktober 2008 juga memutuskan bahawa "pengkid", iaitu wanita berketrampilan dan mempunyai gerak laku serta naluri seksual seperti lelaki adalah haram di sisi agama (Noor, 2015). Disebabkan kedudukan ini, status undang-undang golongan transgender tidak diiktiraf di Malaysia sehingga ke hari ini. Walau bagaimanapun, penulis tidak akan membincangkan isu status undang-undang golongan transgender dalam penulisan ini kerana fokus penulis adalah tertumpu pada hak kesihatan komuniti transgender dan bukannya isu pengiktirafan status golongan transgender dari sudut undang-undang dan agama.

\section{HAK KESIHATAN TRANSGENDER MENURUT UNDANG- UNDANG KESIHATAN DI MALAYSIA}

Sejak kemerdekaan Malaysia pada tahun 1957, sistem kesihatan negara ini telah berjaya memberikan rawatan kesihatan yang terbaik buat masyarakat di seluruh negara. Sehingga kini, Malaysia telah mencapai taraf kesihatan yang hampir sama dengan negara-negara maju. Kerajaan telah memainkan peranan yang penting untuk mencapai sehingga ke taraf ini dengan menyediakan kemudahan kesihatan yang terbaik buat rakyat (Nik Rosnah \& Wan Abdullah, 2002). Namun, masih ada individu yang tidak mendapat layanan yang sewajarnya diberikan ketika ingin mendapatkan rawatan kesihatan di Malaysia. Hal ini berbangkit kerana sesetengah pengamal perubatan tidak mengamalkan piawaian yang telah diperuntukkan ketika merawat penyakit. Antara kes yang berlaku, golongan transgender di Malaysia yang dilayan secara negatif oleh pengamal kesihatan. Salah satu sebab mengapa hal ini berlaku adalah kerana penyakit HIV yang sering kali dikaitkan dengan golongan transgender sehingga mereka berasa hak 
kesihatan mereka dinafikan. Bahagian ini akan membincangkan piawaian hak kesihatan tertinggi yang ditetapkan oleh KKM untuk dipraktikkan oleh semua pengamal perubatan di Malaysia.

Untuk mencapai perkhidmatan penjagaan kesihatan yang selamat dan kompeten di negara ini, Majlis Perubatan Malaysia (Malaysian Medical Council - MMC) telah ditubuhkan melalui Akta Parlimen yang diluluskan pada 27 September 1971 dan diwartakan pada 30 September 1971. MMC mempunyai bidang kuasa tatatertib terhadap semua doktor yang berdaftar berdasarkan seksyen 29A (1) Akta Perubatan 1971. Segala aduan dan maklumat yang diterima oleh MMC akan disiasat bagi mengesahkan bahawa seseorang doktor itu telah melakukan kesalahan seperti yang aduan. Sebagai panduan, MMC telah mengeluarkan beberapa Ethical Codes bagi menangani masalah ini. Jika pengamal perubatan melanggar sebarang Ethical Codes yang diperuntukkan oleh MMC, maka menurut Seksyen 30 Akta Perubatan 1971, MMC mempunyai kuasa untuk mengenakan denda serta membuang nama daripada senarai doktor yang berdaftar.

\section{Code of Malaysian Conduct 2019}

Bahagian II daripada kod ini telah menggariskan beberapa jenis kesalahan jenayah dan salah laku profesional yang boleh dikenakan tindakan tatatertib. Segala pengabaian tugas sebagai individu yang profesional serta apa-apa pelanggaran etika perubatan yang serius boleh mengakibatkan tuduhan salah laku dan dikenakan tindakan oleh Lembaga Tatatertib MMC. Code of Malaysian Conduct 2019 menggariskan bahawa pengamal perubatan haruslah memberikan amalan rawatan yang terbaik dengan memberikan layanan yang profesional, cekap dan bertimbang rasa ketika merawat pesakit. Misalnya, jika doktor itu mempunyai kepakaran dalam bidang patologi, maka beliau seharusnya memberikan rawatan yang profesional seperti yang dikehendaki oleh doktor yang mempunyai bidang yang sama. Namun begitu, komuniti transgender masih menyatakan bahawa pakar sakit mental, para doktor dan pakar sakit puan masih tidak berjaya memberikan rawatan profesional kerana mereka masih tidak mempunyai keperluan khusus, maklumat yang tepat dan kurang maklumat untuk merawat pesakit LGBT (Kryss, 2016).

Selain itu, Code of Malaysian Conduct 2019 ini juga mengharuskan seorang doktor untuk mendapatkan persetujuan daripada pesakitnya sebelum memulakan sebarang prosedur. Persetujuan yang sah haruslah dibuat secara sukarela dan tidak dipengaruhi oleh sebarang paksaan serta 
penipuan terhadap pesakit. Setelah pesakit memberikan persetujuannya, beliau haruslah diberikan peluang untuk mendapatkan penjelasan yang lebih lanjut tentang prosedur yang akan dikenakan terhadapnya. Maka, jika individu transgender ingin mendapatkan apa-apa jenis rawatan daripada doktor, individu itu haruslah menzahirkan persetujuannya terlebih dahulu sebelum menerima sebarang rawatan. Selain itu, pengamal perubatan yang berdaftar haruslah bertanggungjawab melindungi maklumat sulit yang diperoleh daripada pesakit. Pengamal perubatan haruslah memastikan bahawa segala maklumat yang diberi tidak didedahkan semasa dokumen berkenaan dengan sejarah pesakit dihantar, diterima, disimpan mahupun ketika dilupuskannya. Jika pengamal perubatan ingin mendedahkan maklumat sulit pesakit, maka ia haruslah mendapatkan persetujuan yang sah terlebih dahulu daripada pesakit sebelum memulakan sebarang tindakan.

Amalan perubatan yang baik adalah apabila kepercayaan penuh wujud antara doktor dengan pesakit serta keluarganya. Oleh itu, doktor haruslah berhati-hati agar tidak merosakkan hubungan tersebut supaya tidak menimbulkan persoalan salah laku profesional. Individu transgender seharusnya mempunyai kepercayaan penuh terhadap doktor yang merawatnya. Jika, doktor itu mengganggu hubungan ini maka, pesakit boleh membuat aduan ke MMC.

Code of Malaysian Conduct 2019 juga menegaskan bahawa pengamal perubatan tidak boleh mengambil bahagian dalam sebarang perlakuan yang berbentuk penyeksaan, kejam, tidak berperikemanusiaan atau apaapa bentuk penghinaan terhadap pesakit termasuk pesakit transgender. Jika berlaku sebarang perlakuan yang tidak berperikemanusiaan terhadap pesakit transgender oleh seorang doktor yang berdaftar, maka dia telah merendahkan martabatnya sebagai seorang pengamal perubatan profesional dan tindakan tatatertib boleh dikenakan terhadapnya. Pada 2018, seorang pengamal perubatan yang bertugas di Hospital Raja Perempuan Zainab II, telah menulis surat terbuka di laman media sosial (facebook), beliau mempersoalkan hak kesihatan golongan LGBT. Walaupun suratnya merupakan komen peribadi dan tidak mewakili mana-mana kementerian, namun komen itu didapati mempunyai unsur diskriminasi. KKM telah mengambil maklum berkenaan dengan surat terbuka tersebut dan telah mengambil tindakan disiplin terhadap pengamal perubatan tersebut serta aduan telah dibuat kepada Biro Pengaduan Awam (Rahim, 2018). Jelas dapat kita lihat bahawa perkara ini berbangkit, kerana adanya stigma negatif dalam kalangan pengamal perubatan terhadap golongan yang 
mempunyai perbezaan orientasi seksual ini. Jika pengamal perubatan bertindak melakukan perkara yang memudaratkan individu transgender disebabkan status sosial mereka, maka Lembaga Tatatertib MMC dalam bidang kuasanya boleh mengenakan tindakan disiplin terhadap pengamal perubatan itu.

\section{Good Medical Practice 2019}

Good Medical Practice 2019 merupakan garis panduan yang disediakan untuk menjelaskan kod profesional yang mengatur bentuk dan cara amalan perubatan pada peringkat antarabangsa. Kod ini telah diterima pakai oleh MMC pada 18 Jun 2019 dan berteraskan prinsip tanggungjawab moral, etika dan sikap profesional yang boleh dipercayai oleh pihak profesion perubatan dan masyarakat. Good Medical Practice 2019 menyatakan bahawa hubungan seorang doktor dan pesakitnya merupakan hubungan yang profesional dan menjadi tanggungjawab doktor memberikan rawatan yang terbaik untuk kesihatan pesakit.

Garis panduan ketiga menekankan hubungan fidusiari antara doktor dan pesakit. Seseorang pengamal perubatan seharusnya memberikan perkhidmatan menurut piawaian penjagaan profesional yang boleh diterima oleh profesion perubatan serta menunjukkan amalan klinikal yang baik dengan menjadi seorang pendengar yang teliti terhadap pesakitnya dan membuatkan pesakitnya berasa selesa di dalam bilik konsultasi. Maka, ketika golongan transgender ingin mendapatkan rawatan, pengamal perubatan tidak seharusnya menilai pesakit berdasarkan identiti jantina mereka. Walau bagaimanapun, masih ada pengamal perubatan yang tidak memberikan rawatan yang sewajarnya kepada komuniti transgender kerana timbulnya stigma terhadap status sosial mereka.

Berdasarkan temu bual yang dibuat oleh Outright Action International pada tahun 2000, seorang wanita transeksual (yang enggan mendedahkan identitinya) telah selesai melakukan pembedahan sex-reaffirming surgery di Thailand dan memohon untuk menukar nama pada kad pengenalannya untuk dipadankan dengan jantina baharunya. Wanita transeksual itu diminta untuk memberikan surat pengesahan daripada pakar sakit puan yang bekerja di hospital kerajaan bagi mengesahkan pembedahan yang dibuat. Doktor pertama yang ditemui di Hospital Kuala Lumpur enggan mengesahan dokumen tersebut kerana beliau percaya bahawa hospital dan kerajaan Malaysia tidak membenarkan sex-reaffirming surgery. Wanita transeksual itu berasa doktor enggan membuat pengesahan atas 
kepercayaan agama sedangkan dan bukan bertindak secara profesional. Wanita transeksual itu seterusnya berjumpa dengan doktor lain yang bukan beragama Islam dan doktor tersebut bersetuju untuk mengesahkan bahawa beliau telah menjalani pembedahan sex-reaffirming surgery (Kryss, 2016). Hal ini menunjukkan bahawa tidak semua pengamal perubatan akur dengan piawaian penjagaan profesional kerana adanya pengaruh agama yang menyebabkan golongan transgender berasa hak mereka dinafikan.

Pengamal perubatan juga harus melayan pesakit dengan penuh tatatertib dan tidak mengeluarkan kata-kata yang boleh menyinggung perasaan pesakit. Pengamal perubatan tidak seharusnya memberikan komen yang berunsur kritikan apabila pesakit memberikan maklumat yang dianggap remeh dan tidak relevan. Akhir sekali, pesakit berhak menerima layanan yang berhati-hati apabila mendapat rawatan daripada pengamal perubatan ketika penilaian fizikal. Jika berlaku sebarang ketidakselesaan, maka doktor itu harus berhenti seketika sebelum meneruskan semula penilaian fizikal.

\section{Code of Professional Conduct for Nurses First Edition April 1998}

Selain doktor, jururawat juga memainkan peranan yang penting untuk menjaga kesihatan dan kesejahteraan masyarakat. Mereka bertanggungjawab memberikan penjagaan yang rapi untuk mengurangkan penderitaan pesakit serta merawat individu, keluarga dan masyarakat. Lembaga Jururawat Malaysia, KKM telah mengeluarkan kod etika yang harus dipatuhi oleh setiap jururawat yang berdaftar. Oleh itu, setiap jururawat yang berdaftar mempunyai kewajipan moral untuk mematuhi prinsip-prinsip yang diperuntukkan dalam Code of Professional Conduct for Nurses 1998 ini. Kod yang pertama menyatakan jururawat seharusnya menghormati pesakit dan tidak menilai mereka. Oleh itu, setiap jururawat perlu merawat dan memberikan rawatan yang terbaik kepada setiap pesakit tanpa mengira asal usul, keadaan kesihatan, agama dan status sosial mereka. Maka, jika pesakitnya ialah individu transgender, jururawat itu seharusnya memberikan rawatan yang sama seperti orang lain tanpa melihat kepada kecenderungan identiti jantina individu itu.

Kod ini juga menggariskan piawaian penjagaan kesihatan yang harus dipatuhi oleh setiap jururawat yang berdaftar. Oleh yang demikian, jururawat perlu memberikan perkhidmatan menurut piawaian penjagaan yang baik dengan meneliti serta menilai semua aspek termasuk keperluan fizikal, psikososial serta rohani setiap pesakit termasuk golongan 
transgender. Jururawat juga memberikan rawatan kepada pesakit secara kompeten bagi memenuhi setiap masalah dan keperluan pesakit. Oleh itu, jika pesakitnya merupakan seorang transgender dan mempunyai penyakit HIV, maka jururawat itu harus menilai keperluan fizikal, psikososial serta rohani pesakit HIV dengan baik.

Berdasarkan Seksyen 32 Akta Jururawat 1950 (Akta 14), Lembaga Jururawat Malaysia mempunyai bidang kuasa disiplin untuk menjatuhkan hukuman kepada jururawat yang berdaftar jika didapati bersalah akibat salah laku atau perkara yang tidak senonoh ketika menjalankan tugasnya dengan membatalkan pendaftaran nama daripada senarai pendaftaran, menggantung nama daripada pendaftaran untuk tempoh yang difikirkan sesuai oleh Lembaga tersebut.

\section{Garis Panduan Pembantu Perubatan Kesihatan Awam}

Pembantu perubatan merupakan pengamal kesihatan yang berkerjasama dengan doktor, terutamanya dalam membantu menyediakan rawatan kepada pesakit luar seperti di pejabat perubatan dan klinik kesihatan. Mereka seharusnya memberikan piawaian profesional dan tatakelakuan yang tinggi seperti yang dikehendaki dalam bidang perubatan. Berdasarkan garis panduan ini, pembantu perubatan haruslah mengutamakan kebajikan pesakit serta memberikan perkhidmatan penjagaan kesihatan yang bermutu tinggi pada setiap masa. Hal ini kerana pembantu perubatan seharusnya mengekalkan amalan piawaian profesional seperti yang dikehendaki oleh doktor dan juga jururawat. Oleh yang demikian, pembantu perubatan juga mempunyai tanggungjawab untuk merawat pesakit transgender dengan memberikan rawatan profesional tanpa menilai kecenderungan jantina mereka.

\section{Kod Etika dan Tatakelakuan Kementerian Kesihatan Malaysia (KKM)}

Kod Etika dan Tatakelakuan KKM ialah satu himpunan nilai dan moral serta panduan yang selaras dengan budaya korporat KKM dan peraturan perkhidmatan awam. Kod ini merangkumi etika kerja dan etika profesional yang harus dipatuhi oleh semua warga KKM serta menjadi panduan dan kawalan kepada warga KKM untuk melaksanakan tugas dan tanggungjawabnya dengan baik. Kod Etika dan Tatakelakuan KKM menggariskan bahawa setiap warga KKM haruslah memberikan 
perkhidmatan yang terbaik kepada semua pesakitnya tanpa diskriminasi kaum, bangsa dan agama. Walaupun jantina tidak dinyatakan secara khusus, namun pesakit transgender masih merupakan pelanggan yang berhak menerima rawatan kesihatan di hospital. Oleh itu, setiap warga KKM seharusnya memberikan perkhidmatan rawatan kesihatan yang berkualiti kepada setiap pelanggannya. Jika warga KKM melanggar sebarang piawaian yang telah ditetapkan dalam kod ini, mereka akan dikenakan tindakan tatatertib di bawah Peraturan-Peraturan Pegawai Awam (Kelakuan dan Tatatertib) 1993.

\section{ANALISIS DAKWAAN DISKRIMINASI TERHADAP GOLONGAN TRANSGENDER DI MALAYSIA}

Dapat kita lihat di sini bahawa KKM telah mengeluarkan garis panduan yang mencukupi berkenaan dengan piawaian rawatan kesihatan yang terbaik buat pengamal kesihatan secara keseluruhannya. Jika garis panduan itu tidak dipatuhi, maka terdapat hukuman yang diperuntukkan oleh Lembaga Tatatertib badan profesional masing-masing. Namun begitu, sehingga hari ini, masih terdapat aduan yang diterima oleh NGO daripada ahli mereka berkaitan dengan diskriminasi yang diterima oleh golongan transgender ketika mendapatkan rawatan kesihatan di hospital kerajaan mahupun swasta.

Untuk mendapatkan data empirikal daripada wakil NGO, penyelidik telah melakukan temu bual. Menurut Responden 1 (2020), golongan transgender masih menghadapi diskriminasi terutamanya apabila ingin mendapatkan akses untuk rawatan hormone replacement therapy (HRT) secara rasmi dan selamat. HRT merupakan suatu proses hormon estrogen diberikan kepada individu transgender agar menghentikan penghasilan hormon testosteron. Hal ini akan mewujudkan perubahan fizikal yang lebih feminin (Mayo Clinic, 2020). Disebabkan pembedahan pertukaran jantina adalah haram dari segi syarak di Malaysia, sebahagian besar daripada komuniti transgender terutamanya yang beragama Islam mengambil keputusan untuk cuba menjalani rawatan HRT tersebut melalui perkhidmatan kesihatan di hospital atau pusat kesihatan. Apabila ditolak, mereka mula melakukan rawatan HRT secara preskripsi-kendiri (selfprescription), tanpa seliaan daripada pakar dalam bidang tersebut. Perkara ini telah mengakibatkan mereka terdedah kepada risiko lebihan dos yang boleh mengakibatkan kematian (Selamat, 2020). 
Selamat (2020) juga berkata ramai pengamal kesihatan tidak menyedari risiko yang dihadapi oleh golongan transgender apabila mereka melakukan HRT secara preskripsi-kendiri. Kemungkinannya berpunca daripada individu itu sendiri apabila mereka kurang selesa untuk bercakap tentang perkara yang melibatkan peralihan jantina atau organ seksual kepada pengamal kesihatan kerana mereka terdiri daripada pekerja seks tetap. Oleh sebab itu, amalan biasa yang mereka lakukan adalah dengan menjalani HRT tanpa preskripsi oleh doktor yang berdaftar untuk mengelakkan stigma masyarakat. Sering kali, pil HRT ini dibeli di farmasi dengan tujuan "mempercepat" proses peralihan jantina (Britton A. Gibson, 2016).

Tanpa akses untuk mendapatkan rawatan HRT berserta preskripsi daripada pakar yang diiktiraf, perkara ini telah menyebabkan mereka menghadapi kesulitan apabila ingin memohon insurans kesihatan dengan efektif. Mereka yang berdaftar dengan agen insurans pula menghadapi masalah ketika ingin membuat tuntutan dengan syarikat insurans. Syarikat insurans menggunakan alasan bahawa pelanggan telah melanggar syarat insurans kerana telah mengambil ubat-ubatan dan rawatan hormon tanpa preskripsi yang rasmi daripada doktor yang berdaftar (Selamat, 2020). Perkara ini terjadi kerana keputusan Muzakarah Jawatankuasa Fatwa Majlis Kebangsaan Bagi Hal Ehwal Ugama Islam Malaysia Kali Ke-4 yang bersidang pada 13-14 April 1982 yang telah mengharamkan pertukaran jantina daripada lelaki kepada perempuan atau sebaliknya melalui pembedahan atau sex-reassignment surgery dan menyebabkan pengamal perubatan di Malaysia tidak menyediakan khidmat pembedahan ini. Disebabkan itu juga, komuniti transgender telah mengambil inisiatif untuk melakukan terapi penggantian hormon (hormone replacement therapy) sebagai salah satu inisiatif lain bagi menggantikan pembedahan ini (Human Rights Watch, 2014). Selamat (2020) mengatakan bahawa pihak penyedia perkhidmatan kesihatan, baik kerajaan mahupun swasta, tidak sewajarnya menggunakan lensa agama ketika memberi perkhidmatan kesihatan kepada komuniti ini.

Penulis berpandangan meskipun komuniti transgender mempunyai hak terhadap kesihatan yang dilindungi oleh undang-undang dan Perlembagaan Persekutuan, skop hak kesihatan tersebut hendaklah selaras dengan Perlembagaan Persekutuan dan undang-undang syariah. Oleh yang demikian, bentuk rawatan kesihatan yang wajib dibekalkan oleh pengamal perubatan adalah tertakluk pada rawatan dan ubatan yang telah ditetapkan oleh undang-undang dan dasar-dasar yang berkaitan seperti yang 
dibincangkan sebelum ini. Maka, keengganan pengamal perubatan untuk melakukan pembedahan sex-reassignment dan memberikan rawatan HRT kepada individu transgender tidak boleh dihujahkan sebagai diskriminasi terhadap hak kesihatan mereka.

Selain kesukaran mendapatkan rawatan HRT, golongan transgender juga menghadapi stigma apabila mereka ingin mendapatkan rawatan HIV dan penyakit jangkitan bawaan seksual (sexually transmitted infectionsSTI). Menurut Malaysia Aids Council (MAC), seramai 111,916 rakyat Malaysia menghidap HIV dari tahun 1986 sehingga setakat 2016 (Siti Amirah Akilah, 2020) dan golongan transgender lebih terdedah kepada penyakit ini kerana jangkitan boleh disebar melalui suntikan dan hubungan kelamin luar tabii seperti male-to-male sex. Selain itu, golongan transgender juga sering dimomokkan oleh pengamal kesihatan kerana perwatakan dan pemakaian golongan ini tidak sama seperti yang tertera dalam dokumen mereka. Misalnya, dalam kad pengenalan individu itu, berpakaian seperti seorang lelaki tulen namun apabila ingin mendapatkan rawatan, mereka berpakaian seperti seorang perempuan dan berperwatakan feminin (Selamat, 2020). Menurut Selamat (2020), hal ini adalah bertentangan dengan etika seorang doktor dan jururawat, kerana mereka seharusnya memberikan rawatan yang terbaik tanpa menilai status sosial pesakitnya itu.

Tambahan itu, Nisha Ayub, seorang aktivis transgender telah menyatakan bahawa terdapat sesetengah doktor yang tidak mahu memeriksa pesakit transgender ketika mereka ingin mendapatkan rawatan dan hanya menyentuh mereka dengan menggunakan pen sahaja (Mohd Husni Mohd Noor, 2018). Hal ini terjadi, disebabkan perkara yang sama, iaitu pandangan negatif masyarakat terhadap pesakit HIV dan STI yang dikaitkan dengan golongan ini. Perkara ini semestinya bertentangan dengan etika moral yang telah digariskan dalam Good Medical Practice 2019 bahawa seorang pengamal perubatan harus mematuhi piawaian tingkah laku peribadi yang betul pada setiap masa serta melayan pesakit dengan penuh tatatertib dan tidak menyinggung perasaan pesakit.

Stigma terhadap pesakit yang hidup dengan HIV atau AIDS adalah sangat ketara di Malaysia. Walaupun terdapat garis panduan yang seharusnya diamalkan oleh pengamal perubatan, antara penghalang golongan ini untuk mendapatkan rawatan kesihatan adalah disebabkan stigma. Sebagai contoh, hal ini dapat dilihat dengan suatu online cross-sectional survey yang dijalankan oleh 1296 pelajar perubatan dan pergigian di tujuh buah universiti di Malaysia pada tahun 2012. 
Keputusan menunjukkan bahawa pelajar perubatan lebih cenderung untuk mengamalkan sikap negatif terhadap pesakit yang mempunyai HIV/AIDS, kerana kurangnya kesedaran tentang penyakit itu, terutamanya pelajar yang mempunyai bidang kepakaran lain seperti pergigian. Kesimpulannya, pengamal kesihatan haruslah bersikap terbuka dengan menangani sikap rasa malu dan rasa takut ketika merawat pesakit HIV/AIDS (Valerie A Earnshaw, 2014).

Tambahan pula, disebabkan undang-undang Syariah yang jelas melarang perbuatan lelaki menyerupai wanita dan sebaliknya, golongan ini menerima diskriminasi yang ketara ketika ingin mendapatkan akses kepada rawatan kesihatan tidak kira rawatan hormon, fizikal mahupun mental. Pada pendapat Responden 1 (2020), selagi pengamal perubatan sedar bahawa agama adalah perkara peribadi, dan berpegang teguh kepada sumpah Hippocrates, mereka tidak akan bersikap diskriminasi terhadap golongan transgender. Selain itu, Responden 1 juga berpendapat bahawa polisi dan undang-undang sedia ada harus digubal dan dilaksanakan berdasarkan fakta dan bukanlah dogma semata-mata (Selamat, 2020). Disebabkan dogma dan stigma, golongan transgender berasa terpinggir, sunyi dan keseorangan (KKM \& Bahagian Pembangunan Kesihatan Keluarga, 2017).

\section{KESIMPULAN}

Melalui perbincangan dalam manuskrip ini, penyelidik telah mengupas waad, konvensyen, deklarasi serta perjanjian pada peringkat antarabangsa yang mengiktiraf hak asasi manusia terhadap kesihatan seperti yang termaktub di dalam DHAMS, ICESCR, Yogyakarta Principles dan CEDAW. Perjanjian-perjanjian ini telah meletakkan piawaian yang tertinggi pada peringkat antarabangsa untuk dijadikan panduan apabila ingin merawat pesakit tanpa mengira status sosial mereka. Perjanjian serantau seperti ASEAN Declaration of Human Rights juga telah menjelaskan bahawa setiap rakyat negara anggota adalah sama di sisi undang-undang dan perlu mendapatkan layanan yang sama rata tanpa mengira latar belakang mereka. Individu transgender haruslah mendapatkan perlindungan hak kesihatan di bawah undang-undang dan penafian hak akan menyebabkan perlanggaran hak asasi deklarasi ini.

Seterusnya, seperti yang dibincangkan KKM melalui MMC, Lembaga Jururawat Malaysia dan badan profesional yang lain telah menggariskan panduan tentang kod etika buat pengamal perubatan dan 
petugas kesihatan untuk memberikan rawatan yang terbaik kepada pesakit berteraskan tanggungjawab moral, etika dan tatatertib yang baik seperti yang dikehendaki oleh bidang mereka. Walaupun prinsip etika ini telah digariskan oleh KKM, masih berlaku kejadian diskriminasi dan penafian hak kesihatan terhadap golongan transgender.

Responden telah mengatakan antara masalah yang dihadapi oleh golongan transgender adalah ketika mereka ingin mendapatkan HRT kerana sex- reassignment surgery yang telah diharamkan oleh Muzakarah Jawatankuasa Fatwa Majlis Kebangsaan Bagi Hal Ehwal Ugama Islam Malaysia Kali Ke-4 yang bersidang pada 13-14 April 1982. Disebabkan kebolehjangkitan HIV banyak berlaku di antara komuniti transgender, golongan ini menerima diskriminasi ketika ingin mendapatkan rawatan kesihatan kerana stigma sosial yang ada pada sesetengah petugas kesihatan. Kerajaan Malaysia seharusnya melihat diskriminasi terhadap golongan transgender sebagai suatu isu yang serius berikutan masalah yang dilontarkan oleh golongan ini. Golongan transgender berasa bahawa mereka tidak layak dilayan sebegitu oleh pengamal kesihatan di Malaysia. Mereka haruslah melayan semua pesakitnya dengan sama rata dan secara profesional tanpa memandang latar belakang pesakit seperti kaum, warna kulit dan status sosial. Hal ini adalah kerana, pada mereka hak kesihatan adalah sebahagian dari hak asasi manusia yang harus diberikan kepada setiap golongan masyarakat. Perkara ini dipersetujui oleh penulis, namun skop hak kesihatan golongan transgender hendaklah berlandaskan Perlembagaan Persekutuan dan undang-undang domestik lain yang relevan.

Akhir sekali, di Malaysia, walaupun menjadi wanita dan lelaki transgender adalah kesalahan besar dari sudut undang-undang Syariah, tidak bermakna transgender harus dilayan secara tidak adil. Hal ini kerana, Perlembagaan Persekutuan telah menggariskan bahawa konsep kesamarataan adalah terpakai dalam kenikmatan terhadap hak kesihatan. 


\section{RUJUKAN}

Asia Pacific Transgender Network. (2017). Legal gender recognition in Malaysia: A legal \& policy review in the context of human rights. Asia Pacific Transgender Network, pp. 1-85.

Britton A. Gibson, S.-E. B. (29 January, 2016). US National Library of Medicine National Institutes of Health. Retrieved from Gender identity, healthcare access, and risk reduction among Malaysia's mak nyah community: https:// www.ncbi.nlm.nih.gov/pmc/articles/PMC4983682/

Carlos Galina. (20 December, 2019). Council on foreign relations. Retrieved from What is ASEAN?: https://www.cfr.org/backgrounder/whatasean\#: : text $=$ The $\% 20$ Association $\% 20$ of $\% 20$ Southeast $\% 20$ Asian $\% 20$ Nations\%20(ASEAN)\%20is\%20a\%20regional,Singapore\%2C\%20 Thailand\%2C\%20and\%20Vietnam.

Fadilla Shaharom \& Mohamatayuding Samah. (2017). Ratifikasi Cedaw di Malaysia: Kesan menurut undang-undang dan hukum syara'. Journal of Shariah Law Research, 1-28.

Gillian MacNaughton. (29 August, 2013). Untangling equality and nondiscrimination to promote the right to health care for all. Health and Human Rights Journal .

Human Rights Watch. (24 September, 2014). Retrieved from Malaysia: Transgender people under threat: https://www.hrw.org/news/2014/09/24/ malaysia-transgender-people-under-threat

Johan, S. (29 April, 2019). Sinar Harian. Retrieved from Pembahagian kuasa Persekutuan dan negeri-negeri: https://www.sinarharian.com.my/ article/25800/KOLUMNIS/Pembahagian-kuasa-Persekutuan-dan-negerinegeri

Kaspert Lippert-Rasmussen. (December, 2013). What is discrimination? Researchgate, pp. 1-56.

Kementerian Kesihatan Malaysia \& Bahagian Pembangunan Kesihatan Keluarga. (2017). Garis panduan pengendalian masalah kesihatan gender di klinik kesihatan. Wilayah Perseketuan Putrajaya, Malaysia.

Kryss. (2016 May, 2016). Violence: Through the lens of lesbians, bisexual women and transgenders in Malaysia. Outright Action International, 18-20. Retrieved from Violence through the Lens of Lesbians, Bisexual Women and Transgenders in Malaysia .

Mayo Clinic. (14 April, 2020). Feminizing Hormone Therapy. Retrieved from https://www.mayoclinic.org/tests-procedures/feminizing-hormone-therapy/ about/pac-20385096

Mohd Husni Mohd Noor. (10 August, 2018). Transgender tidak harus ditindas. Retrieved from Berita Harian: https://www.bharian.com.my/berita/ nasional/2018/08/460514/transgender-tidak-harus-ditindas 
Nik Rosnah \& Wan Abdullah. (2002). Medical regulation in Malaysia: Towards an effective regulatory regime. ScienceDirect, 96-124.

Noor, U. M. (16 October, 2015). Laman Web Rasmi Pejabat Mufti Wilayah Persekutuan. Retrieved from Isu transgender, tasyabbuh atau penyerupaan: Hukumnya: https://muftiwp.gov.my/artikel/bayan-linnas/1820-siri-5-isutransgender-tasyabbuh-atau-penyerupaan-hukumnya-edisi-kemaskini

Office of the United Nations High Commissioner of Human Rights. (2008). The right to health. $O H C H R$, pp. 1-52.

Official Portal Attorney's General Chambers Malaysia. (2016). Human rights. Retrieved from http://www.agc.gov.my/agcportal/index.php?r=portal2/ left\&menu_id=L2YvK3oycE5FSlg1NGNmTGFJdINIdz09

OHCHR. (5 July, 2017). United Nations Human Rights Office of the High Commissioner. Retrieved from Committee on the Elimination of Discrimination against Women examines the situation of women in Thailand: $\quad$ https://www.ohchr.org/EN/NewsEvents/Pages/DisplayNews. aspx? NewsID $=21846 \&$ LangID $=\mathrm{E}$

Post, R. H. (2015). Enhancing LGBTI rights by changing the interpretation of CEDAW? Nordic Journal of Human Rights, 1-19.

Rahim, N. F. (14 August, 2018). Kenyataan Dr Nur Ilyani, komen peribadi. Retrieved from Berita Harian: https:/www.bharian.com.my/berita/ nasional/2018/08/461657/kenyataan-dr-nur-ilyani-komen-peribadi

Roux, K. (15 12, 2015). IFRC. Retrieved from Red Cross opens first clinic for transgender community in Asia: https://www.ifrc.org/en/news-andmedia/news-stories/asia-pacific/thailand/red-cross-opens-first-clinic-fortransgender-community-in-asia-70749/

Selamat, M. (7 May, 2020). Hak kesihatan transgender di Malaysia. (I. Jasri, Interviewer)

Shamrahayu Abdul Aziz. (13 November, 2014). Berita Harian. Retrieved from Undang-undang mesti selaras Perlembagaan: Undang-undang mesti selaras Perlembagaan

Siti Amirah Akilah Abd Rahim, H. A. (2020). Transgender di Malaysia (Transgender In Malaysia). UMRAN - International Journal of Islamic and Civilizational Studies, 6-10.

Tedros Adhanom Ghebreyesus. (10 December, 2017). Retrieved from World Health Organization: https:/www.who.int/mediacentre/news/statements/ fundamental-human-right/en/ 